\title{
Situación epidemiológica de la leptospirosis humana en Centroamérica, Suramérica y el Caribe
}

\section{Adriana Pulido-Villamarín ${ }^{1 凶}$, Gustavo Carreño-Beltrán ${ }^{1}$, Marcela Mercado-Reyes ${ }^{2}$, Paola Ramírez-Bulla ${ }^{2}$}

\section{Epidemiology of human leptospirosis in Central America, South America and the Caribbean}

\begin{abstract}
To identify and describe the epidemiological status of human leptospirosis or Weil's disease, we searched scientific publications and reports issued by health control authorities from 2006 to 2013. Information extraction was done independently and the methodological quality of the articles was evaluated using a checklist created for that purpose. The country with the highest incidence of human leptospirosis was Trinidad \& Tobago (22 cases per 100,000 people) and the highest percentage of cases occurred in Guyana (60\%). In Colombia, the department with the highest percentage of cases was Antioquia (85.7\%) and the highest incidence was in Cordoba $(67.9 \%)$. Contact with animals is possibly the highest risk factor; its diagnosis is commonly accomplished using a microscopic agglutination test. The analyzed data presented various epidemiological aspects, making it difficult to merge the information. Only in some countries is the academic and governmental interest and awareness evident in the area of public health.
\end{abstract}

Keywords: Human leptospirosis; prevalence; risk factor; diagnosis; Leptospira spp.; Colombia.

Edited by Alberto Acosta $\square$

1 Unidad de Investigaciones Agropecuarias (UNIDIA).

Departamento de Microbiología. Facultad de Ciencias. Pontificia

Universidad Javeriana. Bogotá, Colombia.

2 Grupo de Enfermedades Infecciosas. Departamento de

Microbiología. Facultad de Ciencias. Pontificia Universidad Javeriana.

Bogotá, D.C., Colombia.

Received: 28-03-2014 Accepted: 24-04-2014

Published on line: 27-05-2014

Citation: Pulido-Villamarín A, Carreño-Beltrán G, Mercado-Reyes M, Ramírez-Bulla P (2014) Situación epidemiológica de la leptospirosis humana en Centroamérica, Suramérica y el Caribe (2006-2013). Universitas Scientiarum 19(3): 247-264 doi: 10.11144/Javeriana.SC19-3.selh

Funding: N/A

Electronic supplementary material: N/A

\section{Introducción}

La leptospirosis humana es una infección zoonótica producida por una bacteria perteneciente al phylum Sprirochaetes, orden Spirochaetales, familia Leptospiraceae del género Leptospira (Holt et al.1986), que a su vez fue divido en tres subgrupos. En el primero, se encuentran especies saprofíticas (seis especies), en el segundo están las especies patógenas (nueve especies) y en el último, denominado "grupo indeterminado" (seis especies) se encuentran las especies que no se les ha comprobado patogenicidad (Ko et al. 2009, Bello et al. 2013); sin embargo filogenéticamente todas pertenecen a un grupo monofilético altamente relacionado (Gupta et al. 2013). En el segundo grupo 
de especies patógenas se encuentra L. interrogans con más de 200 serovares patógenos, que poseen especificidad de hospedero sin ser completamente exclusivas de ellos (Levett 2001, Bharti et al. 2003, Ko et al. 2009, Goncalves de Albuquerque et al. 2012) por lo que pueden desencadenar cuadros de tipo zoonótico. Morfológicamente estas bacterias son bacilos móviles Gram negativos, helicoidales, aerobios estrictos que miden $0,1 \mu \mathrm{m}$ de diámetro y 6 a $12 \mu \mathrm{m}$ de longitud (Winn et al. 2006).

De acuerdo con la Organización Mundial de la Salud (OMS), una zoonosis se define como la transmisión de cualquier enfermedad o infección de animales vertebrados a humanos (WHO 2013b) y viceversa, como es el caso de la leptospirosis, donde los principales animales involucrados son roedores, caninos, porcinos, bovinos, ovinos, equinos e incluso murciélagos, con quienes el ser humano tiene contacto directo; sin embargo, el principal reservorio y transmisor animal es el roedor (Ferro et al. 2006).

La bacteria se localiza principalmente en los túbulos renales de los animales portadores, colonizando persistentemente este sitio para luego ser eliminados por la orina (Álvarez et al. 2011), esta a su vez, contamina el agua de ríos, lagos y demás fuentes hídricas que son utilizadas para uso comercial, agrícola, ganadero o ser consumida por el ser humano y animales, por lo que ingresan al humano vía oral o través de heridas superficiales, mucosas o conjuntivas (Forbes et al. 2007, Góngora etal. 2008, Hartskeerl etal. 2011, Jobbins et al. 2014). Una vez el microorganismo ingresa al torrente sanguíneo (leptospiremia), se dirige hacia el hígado y a los riñones donde se ubica gracias al alto contenido de ácidos grasos, los que posteriormente serán metabolizados por $\beta$ - oxidación para su crecimiento, facilitando la formación de biopelículas (Adler \& De la Peña 2010, Goncalves de Albuquerque et al. 2012). Posteriormente, se presentan dos etapas en el proceso de enfermedad, en la etapa inicial aparecen síntomas como dolores musculares, dolor de cabeza severo, escalofríos y fiebre (Acevedo et al. 2012) y en la segunda etapa conocida como fase inmune, durante la segunda y tercera semana post infección se detectan temperaturas altas debido al proceso inflamatorio que se desencadena gracias a las moléculas de adhesión de la superficie bacteriana (Adler \& De la Peña Moctezuma 2010). Ocasionalmente, se puede presentar meningitis aséptica donde el 50\% de los enfermos presentan pleocitosis (Winn et al. 2006, Beers et al. 2007). Las lesiones provocadas por la bacteria en el riñón ocasionan insuficiencia renal, mientras la insuficiencia hepática se debe a la lisis eritrocitaria, produciendo hiperbilirrubinemia que genera ictericia, lo que se observa entre el 5 y el $15 \%$ de los casos, signos característicos de la enfermedad de Weil (Ausina \& Moreno 2005, Acevedo et al. 2012).

La enfermedad de Weil, es el estado grave o crónico de la leptospirosis en la cual se observa ictericia, insuficiencia renal aguda y hemorragias causadas por lesiones de capilares y epitaxis (Winn et al. 2006, Beers et al. 2007), debido a que se genera una isquemia localizada por la vasculitis (Adler \& De la Peña Moctezuma 2010). Estos síntomas aparecen desde la tercera a la sexta semana de la enfermedad; las anomalías renales que se desencadenan son uremia, hematuria, piuria y proteinuria, dada la obstrucción de los túbulos renales y por presencia de la bacteria en la luz tubular de las nefronas. A su vez, se presenta glomerulonefritis por la presencia de complejos inmunes, cuyas lesiones inician en el glomérulo y luego pasan a los túbulos intersticiales; donde adicionalmente se produce la formación de biopelículas (Beers et al. 2007). La aparición de una insuficiencia pulmonar es ocasionada por una neumonitis hemorrágica grave con daño vascular, siendo actualmente reconocida como el Síndrome Pulmonar Hemorrágico asociado a leptospirosis (LPHS por su sigla en inglés), atribuidos a la presencia de cepas patógenas, que lo han llevado a considerarse un síndrome emergente diferente a la enfermedad de Weil (Ko et al. 2009). Se observan casos raros de la enfermedad en donde se presenta iridociclitis, neuritis óptica, neuropatía periférica y en mujeres en estado de embarazo puede causar aborto (Beers et al. 2007). Los casos de mortalidad son raros, pero se pueden presentar por la poca especificidad en la sintomatología, por desconocimiento de la enfermedad o por un diagnóstico de laboratorio inadecuado.

Debido a la diversidad de manifestaciones clínicas que se presentan y por su similitud con otras patologías, es esencial contar con una buena anamnesis y con el apoyo de pruebas de laboratorio que permitan conducir al médico hacia el diagnóstico definitivo. Por lo anterior y de acuerdo con la OMS, 
la prueba de oro es la Aglutinación Microscópica o Microaglutinación (MAT) (WHO 2003) que consiste en observar en campo oscuro la aglutinación por unión antígeno-anticuerpo frente a los serovares más comunes de L. interrogans, como: Icterohaemorrhagiae, Grippotyphosa, Pomona, Sejrohardjo y Canicola, entre otros; sin embargo, esta prueba no identifica el tipo de anticuerpo que se encuentra en la muestra ( $\mathrm{IgM} \mathrm{o} \mathrm{IgG)}$ (Vanasco et al. 2007, Shelotto et al. 2012). Otra de las pruebas diagnósticas es el ELISA indirecto donde se buscan anticuerpos IgG o IgM, esta técnica puede detectar anticuerpos no aglutinantes en los primeros días después de los síntomas (Vanasco et al. 2007, Céspedes et al. 2009, Vasconcellos et al. 2010). Otra técnica serológica es la Inmunofluorescencia Indirecta (IFI) que detecta anticuerpos IgG o IgM (Khandan \& Mehrabian 2012) y por último la Hemoglutinación que consiste en observar la aglutinación de glóbulos rojos (Grupo O Rh Negativo) sensibilizados con cepas de Leptospira spp. en contacto con el suero del paciente que contiene IgM o IgG (Obregon et al. 2005, Perret et al. 2005). En cuanto a los cultivos microbiológicos, el medio de cultivo que ha dado mejores resultados es el EMJH (Ellinghausen McCullough Johnson Harris) (Céspedes et al. 2009), que contiene cloruro de amonio como fuente de nitrógeno y tiamina, factores importantes en el crecimiento, fosfato de sodio dibásico y fosfato de potasio monobásico que son agentes amotiguadores de $\mathrm{pH}$ y cloruro sódico que genera el equilibrio osmótico (Becton Dickinson and Company; BD 2000). En las técnicas moleculares está la Reacción en Cadena de la Polimerasa (PCR), que busca la amplificación de un fragmento del gen ribosomal 16S rRNA, característico de Leptospira spp. y de las espiroquetas (Limmathurotsakul et al. 2012).

De acuerdo con lo reportado por la OMS, el número de casos de leptospirosis en humanos en el mundo no ha sido completamente documentado, ya que en muchas zonas la enfermedad no es correctamente diagnosticada o porque los casos no son reportados como leptospirosis, debido a que otras enfermedades presentan los mismos signos y síntomas. Sin embargo, esta organización ha establecido una probabilidad de 1 caso por cada 100.000 personas por año en climas templados y 10 casos por cada 100.000 personas por año en climas tropicales húmedos (WHO 2013a), condiciones climáticas que predominan en
Centroamérica, Suramérica y el Caribe. A nivel científico, en esta zona de América se han publicado diferentes artículos de investigación en los que se reportan casos clínicos de leptospirosis; sin embargo, no son suficientes para conocer el estado epidemiológico de la leptospirosis en humanos, especialmente si se tiene en cuenta que en esta región predominan climas tropicales y que las principales actividades para el sustento de vida de las familias son la agricultura, la ganadería y la porcicultura, además de tener contacto con roedores, caninos y otros animales (Ferro et al. 2006, Álvarez et al. 2011). Estas labores se dan bajo condiciones ambientales y culturales, que favorecen la diseminación de la bacteria, por lo anterior, con el presente documento se busca presentar información actualizada con respecto a los aspectos epidemiológicos de la leptospirosis humana en Centroamérica, Suramérica y el Caribe, con el fin de ubicar en un mapa los datos obtenidos para que de manera gráfica sea posible una interpretación a la situación actual, asociada además a posibles factores de riesgo, metodologías o avances tecnológicos en el diagnóstico.

\section{Materiales y métodos}

Recolección de datos: Se realizaron búsquedas de información científica acerca de leptospirosis y enfermedad de Weil en humanos, en los países de Centroamérica, Suramérica y el Caribe en bases de datos como: Pub-med, ISI Web of Science, Ebsco Host, Science Direct, SciELO, Redalyc y Latindex. Se localizaron artículos científicos, casos clínicos, avances de diagnóstico publicados y posibles factores de riesgo en revistas indexadas; para ello se utilizaron palabras claves como: leptospirosis en humanos, enfermedad de Weil, diagnóstico leptospirosis humana y Latinoamérica. Se buscó cada país con su respectivo nombre y la búsqueda se realizó en 3 idiomas (español, inglés y portugués).

Los criterios de inclusión fueron los siguientes: 1) Idioma de la literatura inglés, español y portugués. 2) Publicaciones entre 2006 al 2013. 3) Artículos científicos, casos clínicos, metodologías o avances tecnológicos en diagnóstico, estudios observacionales descriptivos, analíticos y de diagnóstico. 4) Publicaciones de los Países de Centroamérica, Suramérica y el Caribe. 
Se excluyeron: 1) Publicaciones que no proporcionaron información de frecuencias de enfermedad o los datos para poderlas calcular. 2) Publicaciones en las cuales se hacía énfasis en aspectos fisiopatológicos, moleculares o inmunológicos de la bacteria. 3) Publicaciones que reportaran frecuencia de enfermedad solo en animales. 4) Publicaciones en las que el diagnóstico había sido realizado con técnicas no validadas. 5) Publicaciones repetidas.

Una vez fueron seleccionados los artículos, se determinó su pertinencia mediante la verificación de una lista de chequeo previamente elaborada (Tabla 1). La información se organizó en tablas y posteriormente la información epidemiológica obtenida a cerca de la enfermedad, fue localizada en un mapa. Teniendo en cuenta que no todos los artículos reportaban datos específicos de prevalencia e intervalos de confianza, se calculó la proporción de positividad entre los casos sospechosos.

Tabla 1. Lista de chequeo para la evaluación de la calidad de los artículos.

\begin{tabular}{cl}
\hline Item & \multicolumn{1}{c}{ Preguntas } \\
\hline itian pregunta de investigación está definida claramente \\
en el artículo?
\end{tabular}

Para efectos del presente reporte, se realizó una consulta adicional en los ministerios de salud, secretarias de salud y sistemas nacionales de vigilancia de salud en Argentina, Belice, Bolivia, Brasil, Chile, Colombia, Costa Rica, Cuba, Ecuador, El Salvador, Guatemala, Guyana, Haití, Honduras, Jamaica, México, Nicaragua, Panamá, Paraguay, Perú, Puerto Rico, República Dominicana, Trinidad \& Tobago, Uruguay y Venezuela.

Reporte de resultados: Teniendo en cuenta, las diversas formas de presentación de datos epidemiológicos en la información consultada, se enuncian las siguientes definiciones:

Proporción de Casos: Criterio que se aplica para número de casos nuevos de una enfermedad con respecto a los habitantes de una región determinada y en un periodo determinado, reportado generalmente en porcentaje (INS 2013).

Prevalencia: Criterio que se aplica para la proporción total de individuos de un grupo o una población que presentan una característica o evento determinado en un momento o en un período determinado (INS 2013).

Seroprevalencia: Criterio porcentaje de personas de casos nuevos que presenten anticuerpos de una enfermedad en una población determinada y en un periodo determinado (INS 2013).

Incidencia: Criterio que se aplica para número de casos nuevos de una enfermedad en una población determinada y en un periodo determinado, siendo tasas que generalmente se informan x 1000 habitantes o x 100000 habitantes (INS 2013).

Adicionalmente, para determinar el intervalo de confianza de $95 \%$, se utilizó la siguiente ecuación:

IC $95 \%=p \pm 1.96 \sqrt{\frac{p x q}{n}}$

En donde: $\mathrm{p}=$ proporción de seropositividad, $\mathrm{n}=$ número de casos sospechosos, $\mathrm{q}=1$ - proporción de seropositividad.

Teniendo en cuenta que el presente reporte refiere datos de publicaciones y que no es un reporte de tipo experimental que permita calcular Odds Ratio, se hace referencia a los posibles factores de riesgo presentados. 


\section{Resultados}

La búsqueda de la literatura arrojó un total de 362 artículos, que fueron sometidos a verificación del cumplimiento de los criterios de inclusión y exclusión; de estos, 49 cumplieron los criterios de inclusión previamente establecidos. Se excluyeron 313 artículos en los cuales la metodología utilizada no era adecuada, no estaba descrita, no se reportaba proporción de casos, no se reportaban posibles factores de riesgo, no se indicaba la técnica utilizada para el diagnóstico o se encontraban repetidos en más de una base de datos (Figura 1). Los estudios seleccionados fueron registrados en organizadores como EndNote y RefWorks.

Diagrama de flujo del proceso de selección de los artículos 2006-2013

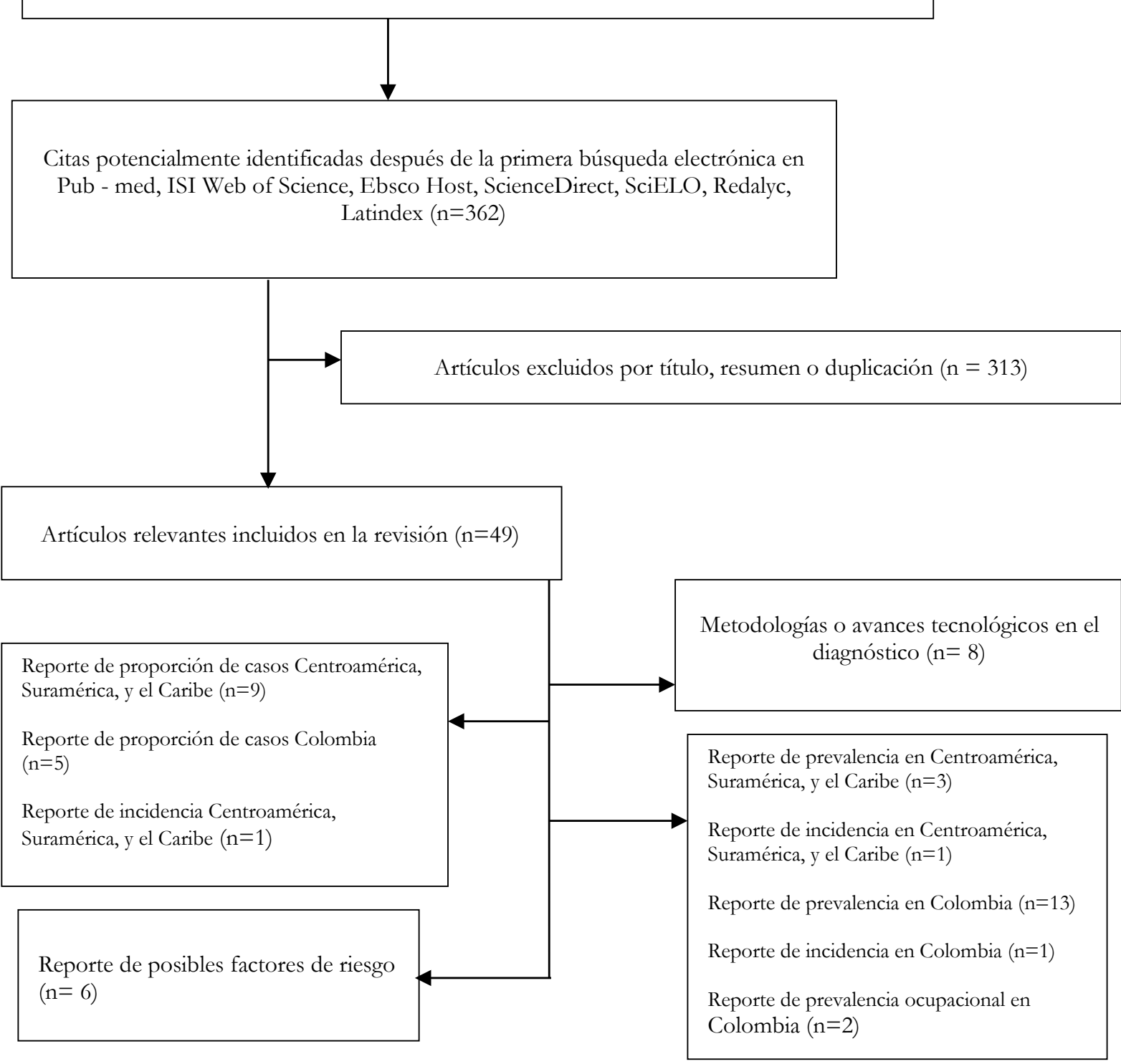

Fig. 1. Selección de artículos acerca de leptospirosis a partir de publicaciones científicas (2006-2013). 
Los datos epidemiológicos hallados son presentados en diferentes parámetros como: proporción de casos
(Tabla 2), prevalencia (Tabla 3) y seroprevalencia (Tabla 4).

Tabla 2. Proporción de casos de leptospirosis reportados en Centroamérica, Suramérica y el Caribe (IC 95\%: Intervalos de confianza del 95\%).

\begin{tabular}{|c|c|c|c|c|c|c|c|}
\hline$\stackrel{\stackrel{0}{E}}{\stackrel{2}{Z}}$ & 是 & 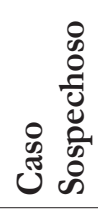 & 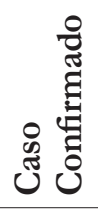 & 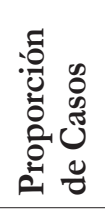 & ํํㅇ & 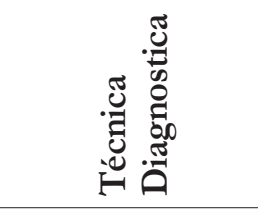 & $\stackrel{n}{\pi}$ \\
\hline Vanasco et al. & 2008 & 812 & 182 & $22,4 \%$ & $(19,6 ; 25,2)$ & MAT & Argentina \\
\hline$\frac{\text { Veltrini \& }}{\text { Langoni }}$ & 2012 & 25 & 2 & $8 \%$ & $(4,4 ; 35,6)$ & MAT & Brasil \\
\hline Rodríguez et al. & 2007 & 293 & 81 & $27,6 \%$ & $(22,5 ; 32,7)$ & MAT & Cuba \\
\hline Berdasquera et al. & 2007 & 885 & 61 & $6,9 \%$ & $(5,3 ; 8,5)$ & $\begin{array}{c}\text { MAT } \\
\text { Hemoaglutinación }\end{array}$ & Cuba \\
\hline Liverpool et al. & 2008 & 108 & 40 & $37 \%$ & $(14,2 ; 29,6)$ & MAT Elisa & Guyana \\
\hline \multirow{4}{*}{ Adesiyun et al. } & \multirow{4}{*}{2011} & 68 & 8 & $11.8 \%$ & $(4,2 ; 19,4)$ & \multirow{4}{*}{ MAT Elisa } & Belice \\
\hline & & 5 & 3 & $60 \%$ & $(17,1 ; 100)$ & & Guyana \\
\hline & & 94 & 30 & $31,9 \%$ & $(22,5 ; 41,3)$ & & Jamaica \\
\hline & & 140 & 12 & $8,2 \%$ & $(3,7 ; 12,7)$ & & $\begin{array}{l}\text { Trinidad \& } \\
\text { Tobago }\end{array}$ \\
\hline Céspedes et al. & 2009 & 268 & 27 & $10,1 \%$ & $(6,5 ; 13,7)$ & MAT Elisa & Perú \\
\hline Céspedes et al. & 2009 & 77 & 21 & $27,3 \%$ & $(17,4 ; 37,2)$ & MAT Elisa & Perú \\
\hline Rodríguez et al. & 2009 a & 292 & 24 & $8,2 \%$ & $(5,1 ; 11,3)$ & PCR MAT & México \\
\hline
\end{tabular}

Tabla 3. Prevalencia de leptospirosis en Centroamérica, Suramérica y el Caribe (IC 95\%: Intervalos de confianza del $95 \%)$.

\begin{tabular}{lccccc}
\hline \multicolumn{1}{c}{ Autor } & Año & $\begin{array}{c}\text { Prevalencia } \\
\text { Casos } / \mathbf{1 0 0 . 0}\end{array}$ & IC 95\% & $\begin{array}{c}\text { Técnica } \\
\text { Diagnostica }\end{array}$ & País \\
\hline Platts-Mills et al. & 2011 & 1,2 & $(0,2 ; 3,6)$ & MAT & Perú \\
Mohan et al. & 2009 & 22 & $(17 ; 22)$ & Elisa & Trinidad \& Tobago \\
Schelotto et al. & 2012 & 13,9 & $(13,1 ; 14,7)$ & MAT - IFI & Uruguay \\
\hline
\end{tabular}


Tabla 4. Seroprevalencia de leptospirosis por departamento en Colombia (IC 95\%: Intervalos de confianza del 95\%).

\begin{tabular}{|c|c|c|c|c|c|c|c|c|}
\hline$\frac{\stackrel{5}{2}}{2}$ & 宗 & 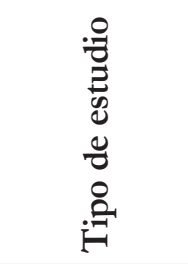 & 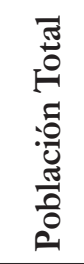 & 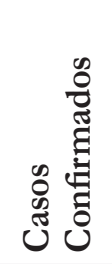 & 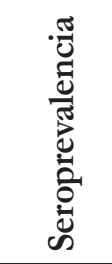 & 응 & 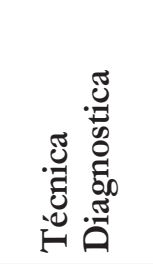 & 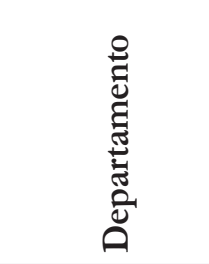 \\
\hline Agudelo et al. & 2007 & $\begin{array}{c}\text { Corte } \\
\text { Transversal }\end{array}$ & 582 & 73 & $12,5 \%$ & $(10,0 ; 15,0)$ & MAT-IFI & Antioquia \\
\hline Ortiz et al. & 2009 & $\begin{array}{c}\text { Corte } \\
\text { Transversal }\end{array}$ & 1307 & 165 & $12,6 \%$ & $(10,9 ; 14,3)$ & MAT & Bogotá D.C. \\
\hline Bermúdez et al. & 2010 & $\begin{array}{c}\text { Corte } \\
\text { Longitudinal }\end{array}$ & 46 & 10 & $21,7 \%$ & $(10,0 ; 33,4)$ & MAT & Boyacá \\
\hline Nájera et al. & 2005 & $\begin{array}{c}\text { Corte } \\
\text { Transversal }\end{array}$ & 344 & 45 & $13,1 \%$ & $(9,6 ; 16,6)$ & MAT & Córdoba \\
\hline Rodríguez et al. (b) & 2009 & $\begin{array}{c}\text { Corte } \\
\text { Transversal }\end{array}$ & 78 & 53 & $67,9 \%$ & $(57,8 ; 78,0)$ & MAT & Córdoba \\
\hline Arteaga et al. & 2009 & $\begin{array}{c}\text { Corte } \\
\text { Transversal }\end{array}$ & 408 & 78 & $19,1 \%$ & $(15,4 ; 22,8)$ & Elisa & Guajira \\
\hline Góngora et al. & 2008 & $\begin{array}{c}\text { Corte } \\
\text { Transversal }\end{array}$ & 503 & 65 & $12,9 \%$ & $(10,2 ; 15,6)$ & Elisa & Meta \\
\hline Díaz et al. & 2008 & $\begin{array}{c}\text { Corte } \\
\text { Transversal }\end{array}$ & 273 & 53 & $19,4 \%$ & $(14,9 ; 23,9)$ & Elisa & Meta \\
\hline Ríos et al. & 2008 & $\begin{array}{c}\text { Corte } \\
\text { Transversal }\end{array}$ & 90 & 12 & $13,3 \%$ & $(6,5 ; 20,1)$ & Elisa & Sucre \\
\hline Romero et al. & 2010 & $\begin{array}{c}\text { Corte } \\
\text { Transversal }\end{array}$ & 850 & 51 & $6 \%$ & $(4,5 ; 7,5)$ & MAT & Tolima \\
\hline Ferro et al. & 2006 & $\begin{array}{c}\text { Corte } \\
\text { Transversal }\end{array}$ & 259 & 59 & $22,7 \%$ & $(17,7 ; 27,7)$ & MAT & Valle del Cauca \\
\hline Arroyabe et al & 2013 & $\begin{array}{c}\text { Corte } \\
\text { longitudinal }\end{array}$ & 220 & 31 & $14.1 \%$ & $(9.5 ; 18.6)$ & MAT-IFI & Antioquia \\
\hline Romero et al & 2013 & $\begin{array}{c}\text { Corte } \\
\text { transversal }\end{array}$ & 128 & 16 & $12,5 \%$ & $(7,7 ; 21,1 \%)$ & MAT & Atlántico \\
\hline
\end{tabular}

La búsqueda en entidades gubernamentales reguladoras de salud, indicó que en la mayoría de los países consultados no se realiza el reporte de notificación obligatoria de la enfermedad; sin embargo, en Chile y Argentina, la notificación de la enfermedad ha sido obligatoria desde el año 2002
(MinSalud2007, Martínez et al. 2012) y en Costa Rica, El Salvador, Honduras y República Dominicana no se tiene conocimiento del año en que comenzó a darse esta notificación de forma obligatoria (SNVSCR 2003, MinSalud 2011, SSH 2011, MinSalud 2012). 


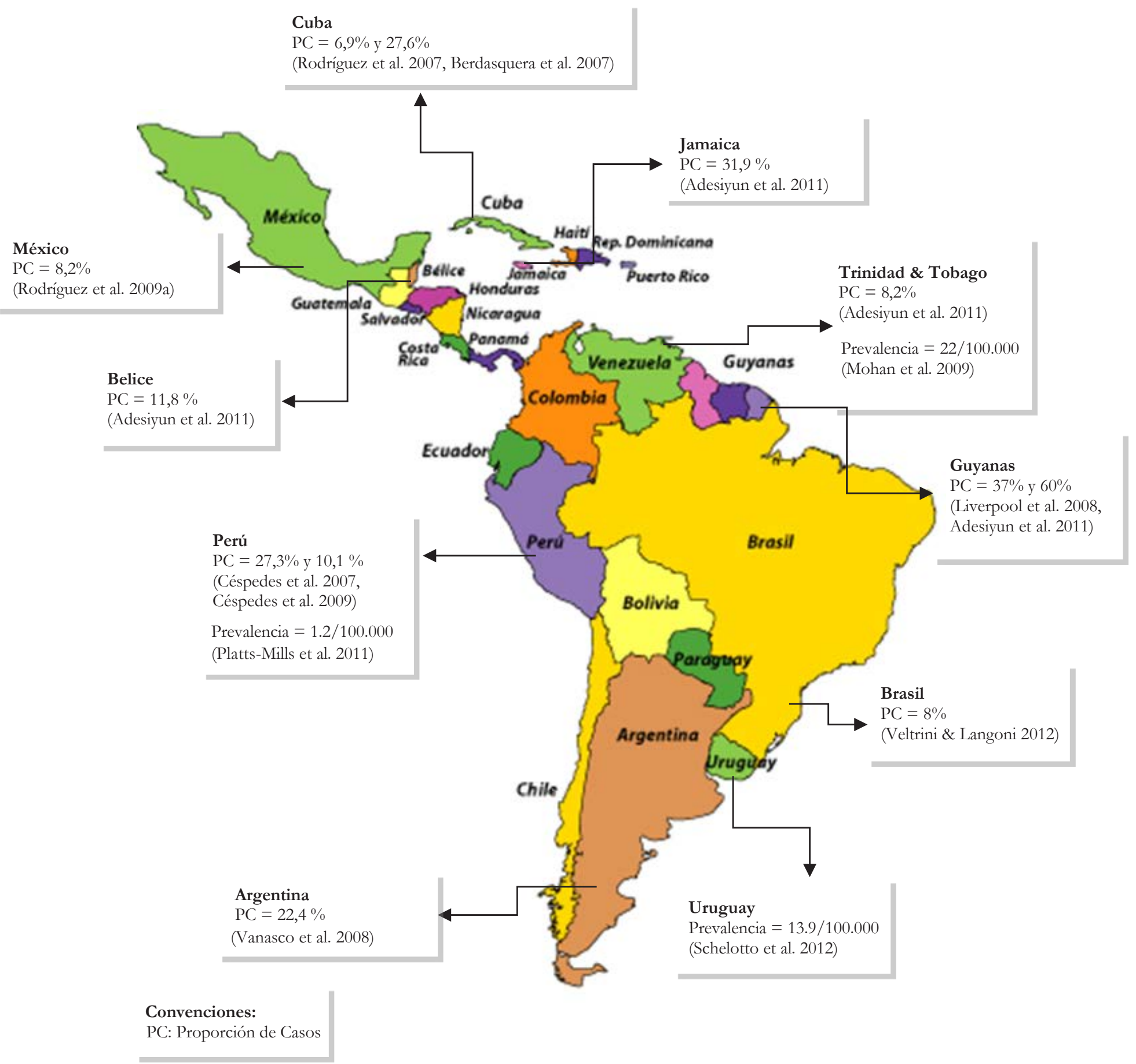

Fig. 2. Proporción de casos y prevalencia de leptospirosis en Centroamérica, Suramérica y el Caribe.

Basados en los resultados obtenidos a partir de la consulta bibliográfica, los datos fueron ubicados en los correspondientes mapas de Latinoamérica (Figura 2) y Colombia (Figura 3). 


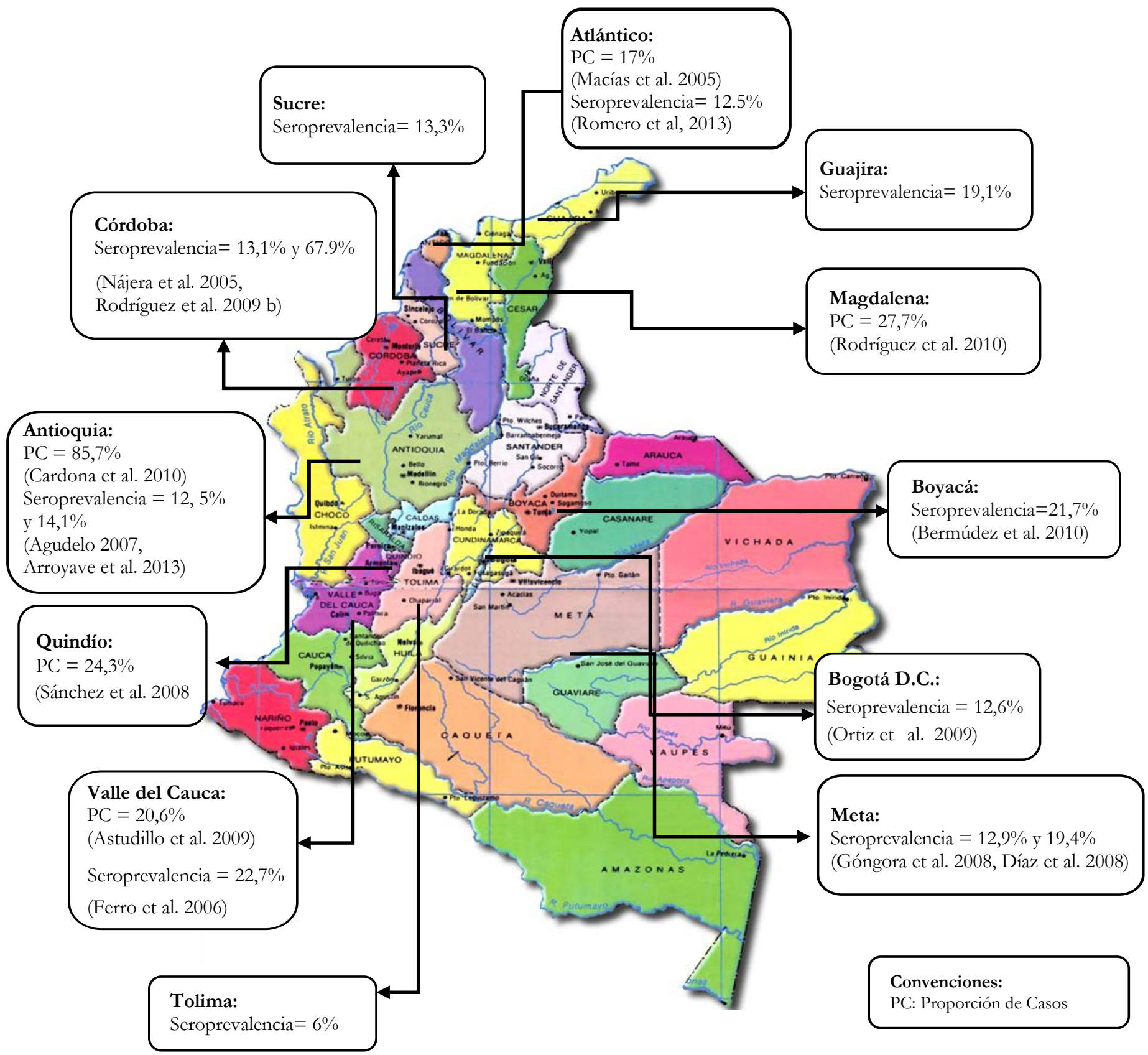

Fig. 3. Proporción de casos y seroprevalencia de leptospirosis en Colombia.

\section{Discusión}

Como lo indican los resultados, aunque fueron detectados abundantes reportes referentes al tema de estudio mediante búsqueda bibliográfica, solo 49 cumplieron con los criterios de inclusión. Sin embargo, la diversidad en la forma de presentación de los datos dificulta su interpretación, razón por la cual fueron agrupados teniendo en cuenta la forma de reporte. En el caso específico de la enfermedad de interés, dado que la prueba de oro es una prueba serológica, los datos de prevalencia y seroprevalencia son sinónimos. Sin embargo, se hace referencia a los dos términos respetando la forma de reporte de las fuentes consultadas. 
Proporción de casos de leptospirosis: Para Centroamérica fueron reportados dos artículos, en México la proporción de casos fue de $8,2 \%$ en una población expuesta (Rodríguez et al. 2009a) y en Belice 11,8\% (Adesiyun et al. 2011), para los demás países no se halló información al respecto. Con respecto a los artículos de Suramérica, se observó que Guyana, es el país que posiblemente presenta mayor proporción de casos de leptospirosis, pues en dos reportes se presentan proporciones de 37\% (Liverpool et al. 2008) y 60\% (Adesiyun et al. 2011), cabe resaltar que estos dos estudios fueron realizados en épocas diferentes y los resultados obtenidos pueden deberse posiblemente a los múltiples factores de riesgo a los que la población se encuentra expuesta. Por otra parte, se encontró una proporción del $8 \%$ de casos en Brasil, siendo la más baja (Veltrini \& Langoni 2012).

En el Caribe, Jamaica presentó la mayor proporción de casos con un 31,9\% (Adesiyun et al. 2011), seguido por Cuba con dos proporciones diferentes 27,6\% (Rodríguez et al. 2007) y 6,9\% (Berdasquera et al. 2007) y Trinidad \& Tobago con $8,2 \%$ (Adesiyun et al. 2011) (Tabla 2).

Esimportante mencionarque además de determinar que los dos países con mayor proporción de casos en Centroamérica, Suramérica, y el Caribe son Guyana seguido por Jamaica, estos datos se obtuvieron a partir de estudios de serie de casos o brotes presentados en un lugar específico de estos países (Figura 2).

En Colombia los estudios reportados, son en su mayoría series de caso. Antioquia tiene el porcentaje más alto del país con 85,7\% (Cardona et al. 2010), aunque el análisis se realizó sobre 7 casos sospechosos. En segundo lugar está el departamento del Magdalena con una proporción de $27,7 \%$ y una letalidad del 20\% (Rodríguez et al. 2010), seguido por Quindío con un $24,3 \%$ presentado una letalidad en los dos años de estudio del 13\% en 2005 y del 3,2\% en 2006 (Sánchez et al. 2008). Por último se encuentran Valle del Cauca y Atlántico presentando proporciones de casos de $20,6 \%$ y $17,7 \%$ respectivamente, lo anterior se debe posiblemente a las condiciones medioambientales, sociales o a la relación sintomatológica con otras enfermedades (Macías et al. 2005, Astudillo et al. 2009) (Figura 3). Como se puede observar en algunos reportes, son evidentes los datos de letalidad, siendo estos preocupantes en salud pública.
Prevalencia de leptospirosis: En relación con los estudios de prevalencia reportados en Centroamérica, Suramérica y el Caribe se observaron prevalencias entre 1,2 casos por cada 100.000 habitantes en Perú (Platts-Mills et al. 2011) y 22 casos por cada 100.000 habitantes en Trinidad \& Tobago, en una población evaluada de 1'262.366 habitantes (Mohan et al. 2009) (Tabla 3), siendo este último el estudio con el mayor número de personas evaluadas en comparación con los demás estudios de prevalencia reportados en este documento (Figura 2).

En Colombia, un estudio realizado en el departamento de Córdoba con población en situación de desplazamiento, reportó una seroprevalencia de 67.9\% (Rodríguez et al. 2009b), en segundo lugar se encuentra el departamento del Valle del Cauca con $22.7 \%$ (Ferro et al. 2006), seguido por Antioquia donde en promedio se reportó con 13.3\% (Agudelo et al. 2007, Arroyave et al. 2013). La capital de Colombia (Bogotá), presentó una seroprevalencia de 12,6\% (Ortiz et al. 2009), cercana a la reportada en Barranquilla del 12,5\%. Tolima reporta la seroprevalencia más baja del país con el 6\% (Romero et al. 2010) (Tabla 4). Estos datos podrían corresponder no solamente a la situación real de la enfermedad, sino también la fuerza académica con la que cuentan Córdoba y Antioquia, donde se localizan grupos de investigación en enfermedades zoonóticas.

De acuerdo con el Sistema de Vigilancia en Salud Pública SIVIGILA de Colombia, la leptospirosis es un evento de notificación obligatoria a partir del año 2007, momento en el cual este sistema fue implementado por el Instituto Nacional de Salud (INS). Se han analizado y reportado resultados de muestras humanas provenientes de diferentes departamentos desde el 2006 mediante las técnicas de MAT y ELISA indirecto, determinando para 2013 una incidencia de 3,03 casos nuevos por cada 100.000 habitantes. Al comparar los datos desde el año 2007 hasta el 2012, se evidencia una disminución de este valor, ya que para el 2007 se presentaron 4,12 casos por cada 100.000 habitantes, siendo el año con más casos reportados. Se observa el comportamiento de la leptospirosis (Figura 4), evidenciando un incremento a partir de 2009, posiblemente dado por la implementación de reportes a nivel nacional o porque efectivamente la patología se fue presentando en mayores proporciones. 


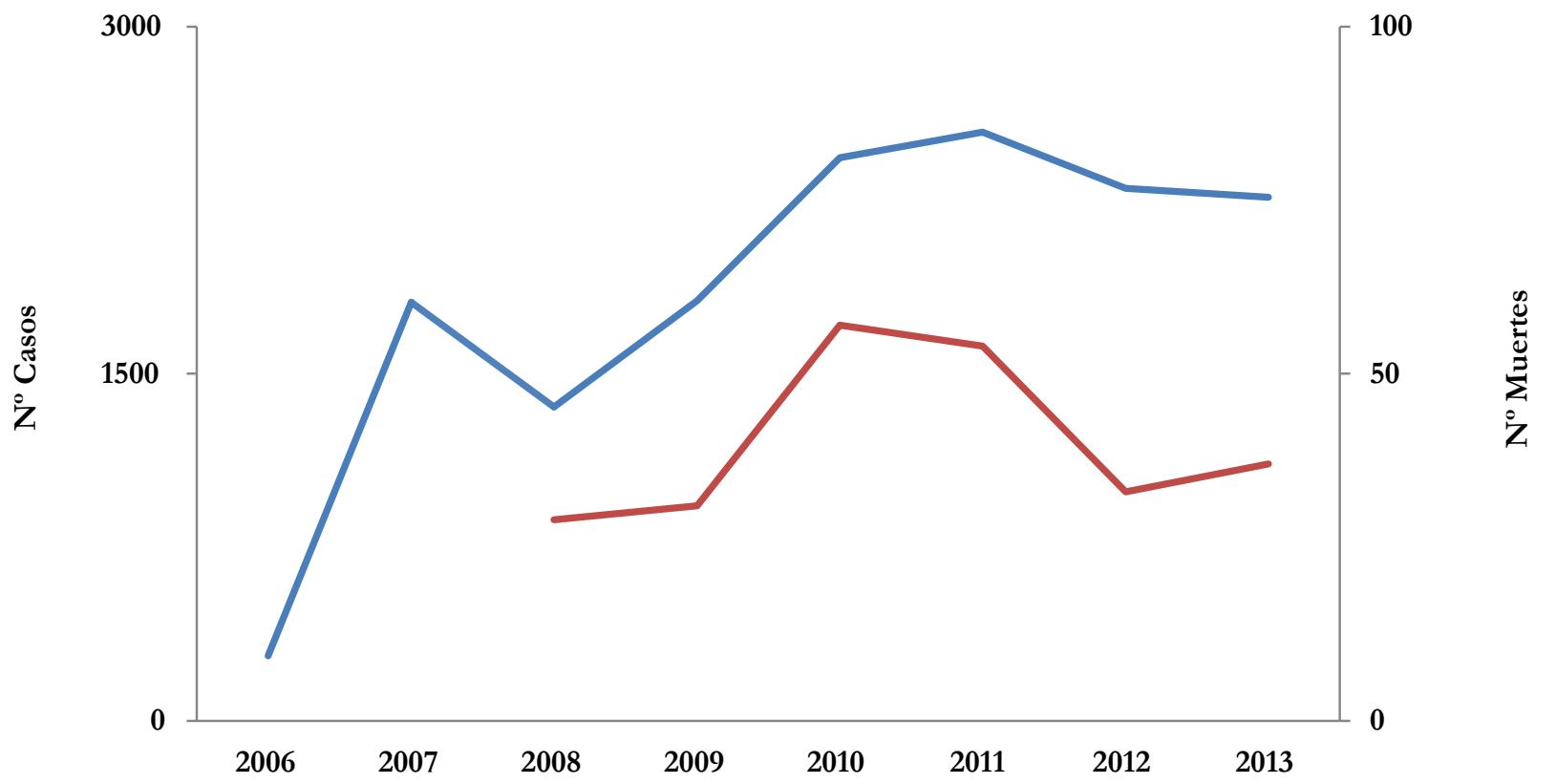

Año

Fig. 4. $\mathrm{N}^{\circ}$ de casos (Azul, en orden cronológico: 281, 1809, 1357, 1816, 2433, 2543, 2301, 2263) y $\mathrm{N}^{\circ}$ de muertes (Rojo, en orden cronológico: 29, 31, 57, 54, 33, 37) de leptospirosis humana 2006-2013 en Colombia.

En lo corrido de 2014, el boletín epidemiológico en semana cinco, ha reportado un total de 256 casos de leptospirosis, con cinco casos de muerte y una incidencia de 0,08 casos por 100.000 habitantes para ese momento; menor, si se compara con la misma semana de 2013 cuando fueron reportados 322 casos con una incidencia de 0,1 casos por 100.000 habitantes. Los datos de muertes por la enfermedad no deberían presentarse, dado que el tratamiento con antibióticos solucionaría la complicación del cuadro clínico. Los departamentos donde se ha presentado la mayor cantidad de reportes son: Guaviare, Antioquia, San Andrés, Cartagena y Magdalena (INS 2014).

Incidencia: Dentro de los datos hallados con esta tasa epidemiológica está Brasil, donde fueron reportadas incidencias de 1,87 y 1,40 respectivamente para los años 2007 y 2008 en la zona este de Sao Paulo, mostrando una disminución de la incidencia de mortalidad que paso de 14,12 en el año 2007 a 12,67 en el año 2008 (Miyazato et al. 2013). Se resalta la importancia de los registros, para conocer realmente el estado epidemiológico de la enfermedad y la importancia de tomar las medidas de control necesarias para dar un tratamiento oportuno y disminuir mortalidades. Ninguno de los demás países del área en análisis reportó esta tasa dentro de sus publicaciones científicas.

Para Colombia, se reportó una tasa de incidencia acumulada de 10,27 casos por 100.000 habitantes, para el periodo de 2007 al 2011, resaltando de manera importante que el estudio incluyó un total de 11.786 registros (Bello et al 2013).

Posibles factores de riesgo: De acuerdo con los conocimientos generales respecto a la transmisión de esta enfermedad son reconocidas la transmisión domiciliaria, recreacional y ocupacional; por lo que en cada una de ellas se presentan diferentes posibles factores de riesgo.

Los posibles factores de riesgo que fueron reportados en los estudios de Centroamérica, Suramérica y el Caribe, están relacionados principalmente con las actividades laborales; es así, como la transmisión ocupacional es considerada 
como el principal factor de riesgo en trabajadores de plantas de sacrificio, veterinarios, agricultores y ganaderos (Vanasco et al. 2008). En segundo lugar está la transmisión recreacional, que se da en personas que tienen contacto con aguas contaminadas como nadadores o conductores de botes rápidos, entre otros (Velasco et al. 2009, Navarrete et al. 2011) y en tercer lugar está la transmisión domiciliaria, que se da en personas que presentan convivencia con roedores o animales domésticos infectados (Schelotto et al. 2012).

Otros posibles factores de riesgo que pueden ser considerados como terciarios o de poco reporte son: presencia de época de lluvias, actividades de natación (incluso en agua tratada), trabajadores en el área de alcantarillado, estudiantes y trabajadores de piscicultura (Schelotto et al. 2012). Lo anterior posiblemente se debe a las condiciones más favorables para que la bacteria pueda sobrevivir fuera de un reservorio, como son las aguas con $\mathrm{pH}$ neutro o ligeramente alcalinas, temperatura de 22 a $30{ }^{\circ} \mathrm{C}$, suelos húmedos y ausencia de exposición a la luz directa del sol (Osés et al. 2010).

Es importante aclarar, que dentro de los posibles factores de riesgo, México reporta que la presencia de enfermedades como dengue o cólera que ocurren principalmente en zonas tropicales y pueden estar relacionadas con el aumento de incidencia de leptospirosis, esto puede ser debido a que en muchos casos, al quedarse sin diagnóstico serológico, pueden ser clasificados como otra enfermedad febril dentro de las que se encuentra la leptospirosis (Navarrete et al. 2011).

En Colombia, se determinó que los posibles factores de riesgo que generan y facilitan la trasmisión de la enfermedad, son en su orden: Convivencia con animales domésticos especialmente con roedores, actividades agrícolas y consumo de agua no potable. También se estableció que entre los factores menos reportados estaban: Ausencia de alcantarillado en las viviendas, actividades laborales como amas de casa, recolectores de basura, piscicultura y estudiantes (no especifican el tipo de estudiante). Como factor de riesgo ocupacional se evaluó el estudio realizado en 2011 en el departamento de Risaralda, donde humanos trabajadores de un zoológico fueron reactivos a los serovares L. bataviae, L. gryppotyphosa y L. hurstbridge deduciendo que posiblemente el contacto con diferentes especies animales portadores generan una seroreactividad (Romero et al. 2011). La ocupación de estudiante, es considerado un posible factor de riesgo en los informes de evento del INS en todos los años, este ha sido uno de los más frecuentemente reportados, pero no se ha generado suficiente información debido a que no se muestra el grado de estudio en los artículos consultados (Tabla 5).

Diagnóstico clínico y de laboratorio: Muchas enfermedades son diagnosticadas clínicamente; sin embargo, una de las dificultades en el diagnóstico de la leptospirosis es su similitud clínica con otras enfermedades tropicales como dengue y malaria. Adicionalmente, la presencia de cuadros ictéricos produce también una confusión con otras patologías como hepatitis; por esta razón, se ha determinado el adecuado y correcto diligenciamiento de los aspectos clínicos en fichas epidemiológicas (Macías et al. 2005, Arroyave et al. 2013), lo cual es soportado en el estudio realizado en México por Zavala et al. (1998), en este estudio, se realizó una comparación de signos y síntomas entre personas que presentaban dengue y leptospirosis, observándose, que no se podía llegar a un diagnóstico específico hasta realizar pruebas diagnósticas de laboratorio que permitieran definir el tipo de microorganismo causante de la patología. De esta manera, se puede deducir que las características clínicas y posibles factores de riesgo no dan indicios claros para clasificar la enfermedad como casos sospechosos; hasta obtener resultados de laboratorio donde se define el diagnóstico con el uso de las diferentes técnicas de identificación (Zavala et al. 1998). De manera similar, en Colombia, el denominado síndrome febril no palúdico es reportado generalmente sin una etiología clara debido a que el diagnóstico definitivo por examen clínico se dificulta por la similitud sintomatológica a pesar de ello, en el Urabá antioqueño, 220 pacientes sintomáticos (negativos a malaria) fueron evaluados para dengue, leptospirosis, rickettsiosis y arenavirus, donde encontraron una seroprevalencia del $2.7 \%$ para Leptospira spp. con algunas infecciones leptospirosisdengue y leptospirosis-dengue-rickettsiosis (Arroyave et al. 2013), ratificando la necesidad de utilizar técnicas diagnósticas de laboratorio para llegar a un dictamen definitivo cuando se parte de un amplio listado de diagnósticos diferenciales, como lo ocurrido en los 
Tabla 5. Posibles factores de riesgo en Colombia según los artículos consultados.

\section{Posibles factores de riesgo}

Contacto directo animales domésticos.

Actividad agrícola.

Actividades de amas de casa.

Actividad de agrícola.

Contacto con orina de animales.

Convivencia con animales.

Pesca.

Amas de casa.

Profesión veterinario.

Actividades agrícolas.

Convivencia con animales domésticos.

Convivencia de animales domésticos y roedores.

Ganaderos.

Recolectores de basura.

Convivencia con animales domésticos y roedores.

Depósitos de agua.

Falta de alcantarillado.

Presencia de animales domésticos.

Falta de acueducto y alcantarillado.

Actividad agrícola.

Convivencia con porcinos.

Actividades piscicultura.

Actividad agrícola.

Médicos veterinarios.

Auxiliares clínicos.

Actividad agrícola.

Convivencia con roedores, animales domésticos en viviendas.

Contacto directo e indirecto con diferentes especies animales.

Actividad de la agricultura y ganadería.

Convivencia con animales domésticos.

Agua no potable.

Convivencia con animales y roedores.
Guajira

(Arteaga et al. 2009)

Meta

\section{Departamentos Autor}

Antioquia

(Agudelo et al. 2007,

Cardona et al. 2010)

Atlántico

(Macías et al. 2005)

Bogotá D.C.

(Ortiz et al. 2009)

Boyacá

(Bermúdez et al. 2010)

Nájera et al. 2005, Rodríguez et al. 2009b)

Córdoba

Magdalena

(Rodríguez et al. 2010)

Quindío

(Sánchez et. al. 2008)

Risaralda

(Romero et al. 2011)

Sucre

(Ríos et al. 2008)

Tolima

(Romero et al. 2010)

Valle de Cauca reportes mencionados. En Puerto Rico, se buscó mejorar el sistema de diagnóstico para la enfermedad generando estrategias de desarrollo en el departamento de salud de los laboratorios clínicos y la revisión de casos confirmados para presentar informes de confirmación (Rivera et al. 2012). 
Como lo reglamenta la OMS, la prueba de Microaglutinación (MAT), es la prueba de oro para el diagnóstico de la enfermedad y el ELISA indirecto es una prueba complementaria para su confirmación (Adesiyun et al. 2011), con éstas técnicas se confirman los casos sospechosos, por lo tanto son las más utilizadas y las más reportadas en los artículos consultados. En Centroamérica, Suramérica y el Caribe según Berdasquera et al. (2007), las técnicas de diagnóstico más utilizadas fueron MAT y ELISA indirecto a partir de muestras humanas (suero y orina). Sin embargo, existen otras técnicas como PCR, hemoaglutinación e inmunofluorescencia indirecta, que son utilizadas en laboratorios especializados o de investigación (OMS 2008) (Tablas 2 y 3).

En Colombia, en general y teniendo en cuenta los reportes, se observó que la mayoría de las técnicas utilizadas para el diagnóstico fueron ELISA indirecto y MAT, según la normativa de la OMS (INS 2011). Una técnica diferente a la prueba de oro y al ELISA es la Inmunofluorescencia indirecta (IFI; Agudelo et al. 2007, Cardona et al. 2010) (Tabla 4), que fue utilizada en el departamento de Antioquia y consiste en la búsqueda de anticuerpos tipo $\operatorname{IgM}$ o $\operatorname{IgG}$ en muestras clínicas (Agudelo et al. 2006, Agudelo et al. 2007, Cardona et al. 2010), esta técnica, puede ser utilizada como diagnóstica de la enfermedad, gracias a que se reporta una sensibilidad de $89,47 \%$, especificidad de $100 \%$, valor predictivo negativo de 95,2\% (IC95\% 82,6 a 99,2) y valor predictivo positivo de 100\% (Agudelo et al. 2006). Es importante aclarar que aunque la PCR no aparece reportada en los artículos consultados para Colombia, si es utilizada como prueba diagnóstica (INS 2009).

Cabe resaltar que la búsqueda bibliográfica aquí citada hace referencia a la leptospirosis humana y que durante su revisión y análisis, el hallazgo de reportes con respecto a leptospirosis en diferentes especies animales y a la detección de Leptospira spp. en muestras ambientales (Romero-Vivas et al. 2013 a,b, Calderón et al. 2014) permiten afirmar que la medicina tanto humana como animal y ahora "ambiental", confluyen en un solo concepto de salud pública ampliando la mirada a la búsqueda de las enfermedades zoonóticas donde sea posible abarcar diferentes puntos de vista.

\section{Conclusión}

La información analizada presenta de diversas formas los aspectos epidemiológicos, dificultando su unificación. En algunos países, es evidente el interés y la concientización académica y gubernamental en esta área de la salud pública; pues a la fecha, solamente en siete países de América (Argentina, Chile, Costa Rica, El Salvador, Honduras, República Dominicana y Colombia) existe la obligatoriedad de reportar los casos de leptospirosis; aunque en la mayoría de países se considera una patología que permanece en alerta epidemiológica.

\section{Conflicto de intereses}

Los autores no tienen conflictos de intereses en relación a este trabajo.

\section{Agradecimientos}

Agradecemos a todas las personas que ayudaron de alguna manera a la elaboración de esta investigación.

\section{Referencias}

Acevedo O, Barreto G, Barreto L, González J, Morales L (2012) Proteína LIC10494 de Leptospira interrogans serovar Copenhageni: modelo estructural y regiones funcionales asociadas. UniversitasScientiarum 17(1):1627

Adesiyun A, Baboolal S, Suepaul S, Dookeran S, StewartJohnson A (2011) Human leptospirosis in the Caribbean, 1997-2005: characteristics and serotyping of clinical samples from 14 countries. Revista Panamericana de Salud Pública 29(5):350-357

Adler B, De la Peña Moctezuma A (2010) Leptospira and leptospirosis. The Servier Veterinary Microbiology 140:287296

Agudelo P, Restrepo B, Arboleda M (2007) Situación de la leptospirosis en el Urabá antioqueño colombiano: estudio seroepidemiológico y factores de riesgo en población general urbana. Cadernos Saúde Pública 23(9):2094-2102

Agudelo P, Restrepo M, Lotero M (2006) Evaluación de la prueba de inmunofluorescencia indirecta para el diagnóstico de Leptospira humana. Biomédica 26:216-223

Álvarez L, Calderón A, Rodríguez V, Arrieta G (2011) Seroprevalencia de leptospirosis Canina en una comunidad rural del municipio de Ciénaga de oro, Córdoba (Colombia). Revista UDCA Actualidad \& Divulgación Científica 14(2):75-81 
Arroyave E, Londoño A, Quintero J, Agudelo-Florea P, Arboleda M, et al. (2013) Etiología y caracterización epidemiológica del síndrome febril no palúdico en tres municipios del Urabá antioqueño, Colombia. Biomédica 33(Supl. 1):99-107

Arteaga L, Restrepo M, Restrepo B, Jiménez M, Bruzon L, et al. (2009) Prevalencia de Leptospirosis en población general de Riohacha y Maicao. Departamento de La Guajira. Revista Icosan http://www.fitogranos.com/ pdf/4/Proyectos.pdf. Consultado 16 Enero de 2013

Astudillo M, González A, Batista N, Mirabal M, Menéndez J (2009) Estudio seroepidemiológico de la leptospirosis humana en el departamento del Valle del Cauca, Colombia. Revista Cubana de Medicina Tropical 61(2):0-0

Ausina V, Moreno S (2005) Tratado SEIMC de enfermedades infecciosas y microbiología clínica. Buenos Aires Argentina

Becton Dickinson and Company (2000) Leptospira medium baseEMJH. [En linea] EstadoUnidos. Becton Dickinson and Company (BD) http://www.bd.com/europe/ regulatory/Assets/IFU/US/S1368\%280600\%29.pdf. Consultado 14 Enero 2013

Beers M, Porter R, Jones T, Kaplan J, Berkwits M (2007) El Manual Merck de Diagnóstico y Terapéutica. ed. El Servier Madrid, España 1615-1616

Bello S, Rodríguez M, Paredes A, Mendivelso F, Walteros D, et al. (2013) Comportamiento de la vigilancia epidemiológica de la leptospirosis humana en Colombia, 2007-2011. Biomédica 33 (Supl. 1):153-160

Berdasquera D, Rodríguez I, Obregón A, Fernández C, Segura R, et al. (2007) Brote de leptospirosis humana en la provincia Guantánamo. Revista Cubana de Medicina Tropical 59(1):1-9

Bermúdez S, Pulido M, Andrade R (2010) Seroprevalencia de Leptospira spp en caninos y humanos de tres barrios de Tunja, Colombia. Revista MVZ Córdoba 15(3):21852193

Bharti A, Nally J, Ricaldi J, Matthias M, Diaz M, et al. (2003) Leptospirosis: a zoonotic disease of global importance. The Lancet Infectious Diseases 12(3):757-771

Calderón A, Rodriguez V, Máttar S, Arrieta G (2014) Leptospirosis in pig, dogs, rodents, humans, and water in an area of the Colombian tropics. Tropical animal bealth and production 46:427-432

Cardona S, Arboleda M, Moreno N, Agudelo P (2010) Brote de leptospirosis en militares de la Fuerza Naval, Turbo, Antioquia. Revista CES MEDICINA 24(2):111

Céspedes M, Tapia R, Balda L, González D, Glenn M, Vinetz J (2009) Brote de leptospirosis asociado a la natación en una fuente de agua subterránea en una zona costera, Lima - Perú. Revista Peruana de Medicina Experimentaly Salud Publica 26(4):441-448
Díaz L, Zapata I, Góngora A, Parra A, Aponte L, Gómez L (2008) Detección de anticuerpos IgM A Leptospira en humanos en riesgo ocupacional en Villavicencio, Meta. Revista MVZ Córdoba 13(1): 1120-1127

Ferro B, Rodríguez A, Pérez M, Travi B (2006) Seroprevalencia de infección por Leptospira en habitantes de barrios periféricos de Cali. Revista Biomédica (26):250257

Forbes B, Sahm D, Weissfeld A (2007) Bailey \& Scott Diagnóstico Microbiológico. Ed Médica Panamericana Madrid España 539-541

Goncalves de Albuquerque C, Burth P, Silva A, Younes M, Castro-Faria-Neto HC, et al. (2012) Leptospira and Inflammation. Mediators of Inflammation 1-11 http:/ / dx.doi.org/10.1155/2012/317950

Góngora A, Parra J, Aponte L, Gómez L (2008) Seroprevalencia de Leptospira spp. en Grupos de Población de Villavicencio, Colombia. Revista salud pública 10(2):269-278

Gupta R, Mahmood S, Adeolu M (2013) A phylogenomic and molecular signature based approach for characterization of the phylum Spirochaetes and its major clades: proposal for a taxonomic revision of the phylum. Frontiers in Microbiology 4:1-18 doi: 10.3389/ fmicb.2013.00217

Hartskeerl R, Collares-Pereira M, Ellis W (2011) Emergence, control and re-emerging leptospirosis: dynamics of infection in the changing world. Clinical Microbiology and Infection 17(4):494-501

Holt J, Krieg N, Sneath P, Staley J, Williams S (1986) Bergey's Manual of Determinative Bacteriology. Ed Williams \& Wilkins 966

INS. Informe del evento leptospirosis, hasta el quinto periodo epidemiológico del año 2013. Proceso vigilancia y control en salud pública. Colombia. 2013. http://www.ins.gov.co/lineas-de-accion/SubdireccionVigilancia/Informe $\% 20 \mathrm{de} \% 20$ Evento $\% 20$ Epidemiolgico/ LEPTOSPIROSIS \%20Periodo \%20V\%202013.pdf. Consultado13 Junio 2013

INS (2009) Comportamiento de la notificación de leptospirosis en Colombia en el año 2008. Proceso vigilancia y control en salud pública Colombia http://www.ins.gov.co/lineas-de-accion/SubdireccionVigilancia/Informe $\% 20 \mathrm{de} \% 20$ Evento $\% 20$ Epidemiolgico/ Leptospirosis\%202008.pdf. Consultado 30 Marzo 2013

INS (2011) Informe de leptospirosis, hasta el décimo tercer periodo epidemiológico del año 2010. Subproceso R02.001 operación y mantenimiento del sistema de vigilancia y control en salud pública. Colombia. http://www.ins.gov.co/lineas-de-accion/SubdireccionVigilancia/Informe \%20de $\% 20$ Evento\%20Epidemiolgico/ Leptospirosis\%202010.pdf. Consultado 30 Marzo 2013 
INS (2013) Informe de leptospirosis, hasta el décimo segundo periodo epidemiológico del año 2012. Proceso vigilancia y control en salud pública. Colombia. http://www.ins.gov. co/lineas-de-accion/Subdireccion-Vigilancia/Informe $\% 20$ $\mathrm{de} \% 20$ Evento $\% 20$ Epidemiolgico/LEPTOSPIROSIS $\% 20$ Periodo\%20XII\%202012.pdf. Consultado 30 Marzo 2013

INS (2014) Boletín epidemiológico semanal. Semana epidemiológica número 05 de 2014 (26 ene. al 1 feb.) http://www.ins.gov.co/boletin-epidemiologico/ Boletn\%20Epidemiolgico/2014\%20Boletin $\% 20$ epidemiologico $\% 20$ semana $\% 2005$.pdf

Jobbins S, Sanderson C, Alexander K (2014) Leptospira interrogans at the Human-Wildlife Interface in Northern Botswana: A Newly Identified Public Health Threat. Zoonoses and Public Health 61:113-123

Khandan N, Mehrabian S (2012) Evaluation of Two Immunodiagnostic Assays (MAT and IFA) for Human Leptospirosis in Gilan Province - Iran. Journal of Microbiology 5(4):582-584

Ko A, Goarant C, Picardeu M (2009) Leptospira: the dawn of the molecular genetics era for an emerging zoonotic pathogen. Nature Reviens 7:736-747

Levett P (2001) Leptospirosis. Clinical Microbiology Reviews 14(2):296-326

Limmathurotsakul D, Turner E, Wuthiekanun V, Thaipadungpanit J, Suputtamongkol Y, et al. (2012) Fool's Gold: Why Imperfect Reference Tests Are Undermining the Evaluation of Novel Diagnostics: A Reevaluation of 5 Diagnostic Tests for Leptospirosis. Clinical Infectious Diseases 55(3):322-331

Liverpool J, Francis S, Liverpool C, Dean G, Mendez D (2008) Leptospirosis: case reports of an outbreak in Guyana. Annals of Tropical Medicine \& Parasitology 102(3):239-245

Macías M, Vergara C, Romero C, Falconar A (2005) Comportamiento de la leptospirosis en el departamento del Atlántico (Colombia). Salud Uninorte 20:18-29

Martínez P, Ortega D, Salinas K (2012) Evolución de la leptospirosis según el Sistema de Vigilancia Epidemiológica Nacional, Chile 2003 - 2009. Revista Chilena de Infectologia 29(6):648-654

MinSalud (2007) Manual de normas y procedimientos de Vigilancia y Control de Enfermedades de Notificación Obligatoria. Argentina http://www.msal.gov.ar/ images/stories/epidemiologia/pdf/manual-normasobligatorias.pdf. Consultado 30 Marzo 2013

MinSalud (2011) Ministerio de Salud El Salvador. Lineamientos Técnicos para la Atención y Control de leptospirosis, Noviembre 2011 http://www.salud.gob. $\mathrm{sv} /$ servicios/descargas/documentos/DocumentaciónInstitucional/Lineamientos-y-Filtros/LineamientosTécnicos-para-la-Atención-y-Control-de-LeptospirosisNoviembre-2011/ Consultado 5 Junio 2013
MinSalud (2012) Enfermedades de notificación obligatoria. Ministerio de Salud Pública. República Dominicana http://www.digepisalud.gob.do/vigilancia-epidemiologica/ enfermedades-de-notificacion-obligatoria.html. Consultado 12 Junio 2013

Miyazato K, Fonseca A, Caputto L, Rocha K, Azzalis L, et al (2013) Incidence of Leptospirosis infection in the East Zone of Sao Paulo City, Brazil. International Archives of Medicine 2013, 6:23 http://www.intarchmed.com/ content/6/1/23

Mohan A, Cumberbatch A, Adesiyun A, Chadee D (2009) Epidemiology of human leptospirosis in Trinidad and Tobago, 1996-2007: A retrospective study. ActaTropica $112: 260-265$

Nájera S, Alvis N, Babilonia D, Álvarez L, Máttar S (2005) Leptospirosis ocupacional en una región del Caribe colombiano. Salud Pública de Mexico 47:240-244

Navarrete J, Moreno M, Rivas B, Velasco O (2011) Leptospirosis prevalence in a population of Yucatan, México. Journal of Pathogens doi: 10.4061/2011/408604

Obregón FA, Fernández MC, Rodríguez J (2005) Leptotekdipstick y leptotekdridot, técnicas útiles en el diagnóstico rápido de la leptospirosis humana. Revista Cubana Higiene y Epidemiologia 43(3):1-8

OMS (2008) Leptospirosis humana: guía para el diagnóstico, vigilancia y control. Traducción del Centro Panamericano de Fiebre Aftosa. - Rio de Janeiro Centro Panamericano de Fiebre Aftosa

Ortiz D, Navarrete J, Pinto C (2009) Prevalencia de leptospirosis en humanos en el Distrito Capital Revista de Investigaciones en Seguridad Socialy Salud 11:51-58

Osés R, Bonet J, Cerero O, Saura G, Pedraza A (2010) Evaluación del comportamiento de la Leptospirosis humana mediante un modelo matemático atendiendo a variables climáticas como predictoras. Revista electrónica de Veterinaria 11 (03B) Consultado15 Junio 2013 http://www.veterinaria.org/revistas/redvet/ n030310B/0310B_DS27.pdf

Platts-Mills J, LaRochelle P, Campos K, Vinetz J, Gotuzzo E, Ricaldi J (2011) Seroprevalencia de Leptospirosis en Puente Piedra,Lima en el año 2006. Revista Peruana de Medicina Experimentaly Salud Pública 28(2):273-276

Perret C, Abarca K, Dabanch J, Solari V, García P, et al. (2005) Prevalencia y presencia de factores de riesgo de leptospirosis en una población de riesgo de la Región Metropolitana. Revista Médica de Chile 133(4):426-431

Rivera B, Bower W, Guerra M, Blau D, Tomashek K, Swaminathan M (2012) Investigation of Leptospirosis Underreporting - Puerto Rico, 2010. Morbidity and Mortality Weekly Report (MMWR) 61(22):421 
Ríos R, Franco S, Mattar S, Urrea M, Tique V (2008) Seroprevalencia de Leptospira sp., Rickettsia sp. y Ehrlichia sp. en trabajadores rurales del departamento de Sucre, Colombia. Infectio 12(2): 319-324

Rodríguez I, Fernández C, Obregón A, Zamora Y, Rodríguez J, et al. (2007) Confirmación microbiológica de 2 brotes emergentes de leptospirosis humana en Cuba. Revista Cubana Medicina Tropical 59(1):1-9

Rodríguez M, Bocanegra V, Acosta R, García E, Bocanegra A, Flores G (2009a) Seropositividad a Leptospira en Trabajadores de Rastros de Tamaulipas. Bioquimia 34(1):92

Rodríguez BH, Lozano MC, Bedoya SC, Grondona L (2009b) Prevalencia de leptospirosis en humanos en la zona urbana del municipio de Puerto Libertador, Córdoba, Colombia. Revista de Investigación Agraria y Ambiental 0(1):23-28

Rodríguez M, Mendivelso F, Heredia D, Rodríguez F, Bello S (2010) Descripción y caracterización del brote de leptospirosis humana en la población de Sabanas de San Ángel, Magdalena-Colombia, marzo de 2009. Informe Quincenal Epidemiológico Nacional 15(3):33-48

Romero M, Astudillo M, Sánchez J, González L, Varela N (2011) Anticuerpos contra Leptospira sp.en primates neotropicales y trabajadores de un zoológico colombiano. Revista de salud pública 13(5):814-823

Romero M, Sánchez J, Hayek L (2010) Prevalencia de anticuerpos contra Leptospira en población urbana humana y canina del Departamento del Tolima. Revista de Salud pública 12(2):268-275

Romero-Vivas C, Cuello-Pérez M, Agudelo-Flórez P, Thiry D, Levett P, et al. (2013a) Cross-sectional study of Leptospira seroprevalence in humans, rats, mice, and dogs in a main tropical sea-port city. The American journal of tropical medicine and higiene 88(1):178-183

Romero-Vivas C, Thiry D, Rodriguez V, Calderón A, Arrieta G, et al. (2013b) Molecular serovar characterization of Leptospira isolates from animals ans water in Colombia. Biomédica 33(Supl. 1): 179-184

Sánchez G, Gómez J, Quintero L, Castaño M (2008) Características clínicas y epidemiológicas de la leptospirosis en el departamento del Quindío, 20052006. Infectio 12(2):96-102

Schelotto F, Hernández E, González S, Del Monte A, Ifran S (2012) A Ten-Year Follow-Up Of Human Leptospirosis In Uruguay: An Unresolved Health Problem. Revista do Instituto de Medicina Tropical de São Paulo 54(2):69-75

SNVSCR (2003) Sistema Nacional de Vigilancia de la salud de Costa Rica. Boletín Epidemiológico 16 al 22 de marzo de 2003 http://www.ministeriodesalud.go.cr/index.php/ boletines/doc_view/518-boletin-vigilancia-de-la-saludsemana-12-de-2003? tmpl=component $\&$ format $=$ raw Consultado 29 Mayo 2013
SSH (2011). Secretaria de Salud de Honduras. Leptospirosis (1) http://www.salud.gob.hn/documentos/dgvs/ Epi\%20alertas/EPILEPTOSPIROSIS2011.pdf. Consultado 5 Junio 2013

Vanasco N, Lottersberger J, Schmeling M, Gardner I, Tarabla H (2007) Diagnóstico de leptospirosis: Evaluación de un enzimoinmunoensayo en fase sólida en diferentes etapas de la enfermedad. Revista Panamerica de Salud Pública 21(6):388-395

Vanasco N, Schmelinga M, Lottersberger J, Costa F, Ko A, Tarabla H (2008) Clinical characteristics and risk factors of human leptospirosis in Argentina (1999-2005). Acta Tropica 107:255-258

Vasconcellos F, Coutinho M, da Silva É, Fernandes C, Monte L, et al. (2010) Testing different antigen capture ELISA formats for detection of Leptospira spp. in human blood serum. Transactions of the Royal Society of Tropical Medicine and Hygiene 104:259-264

Velasco O, Rivas B, Sánchez M, Soriano J, Rivera H, Garibay V (2009) Leptospirosis crónica en México: diagnóstico microscópico y evidencias que respaldan su existencia e importancia. Revista Mexicana de Patología Clínica 56(3):157-167

Veltrini U, Langoni H (2012) Geographic analysis on the occurrence of human and canine leptospirosis in the City of Maringá, State of Paraná, Brazil. Revista da Sociedade Brasileira de Medicina Tropical 45(1):100-105

Winn W, Allen S, Janda W, Koneman E, Procop G, Schereckenberger P, Woods G (2006) Koneman Diagnóstico Microbiológico Texto y Atlas en color. Ed Médica Panamericana Madrid España 1094-1097

World Health Organization (2013a) Enfermedades relacionadas por aguas, Leptopirosis [en línea]. Health Topics World Health Organization. [Ginebra, Suiza] Health Topics. http://www.who.int/water_sanitation_ health/diseases/leptospirosis/en/ Consultado $2 \overline{1}$ Enero 2013

World Health Organization (2013b) Zoonoses [en línea]. Health Topics World Health Organization. [Ginebra, Suiza] Health Topics. http://www.who.int/topics/ zoonoses/en/ Consultado 21 Enero 2013

World Health Organization (2003) Human leptospirosis guidance for diagnosis, surveillance and control.

Zavala J, Vado I, Rodríguez M, Rodríguez E, Barrera M, Guzmán E (1998) Leptospirosis anictérica en un brote epidémico de dengue en la Península de Yucatán. Revista Biomedica (9):78-83 
Situación epidemiológica de la leptospirosis humana en Centroamérica, Suramérica y el Caribe

Resumen. Para identificar y describir el estado epidemiológico de la leptospirosis humana o enfermedad de Weil, se realizó búsquedas de publicaciones científicas y reportes en entes reguladores de salud, durante el periodo 2006-2013. La extracción de información fue independiente y se realizó una lista de chequeo para evaluar la calidad metodológica de los artículos hallados. El país con mayor prevalencia fue Trinidad \& Tobago (22 casos por 100.000 habitantes) y la mayor proporción de casos fue en Guyana (60\%). En Colombia, el departamento con mayor proporción de casos fue Antioquia $(85,7 \%$ ) y el de mayor seroprevalencia, Córdoba (67,9\%). Para diagnóstico, la técnica más utilizada es la aglutinación microscópica y el posible factor de riesgo es por contacto con animales. La información analizada presentó diversos aspectos epidemiológicos, dificultando su unificación. Para algunos países, es evidente el interés y la concientización académica y gubernamental en el área de salud pública.

Palabras clave: Leptospirosis humana; prevalencia; factor de riesgo; diagnóstico; Colombia.
Situaçáo epidemiológica da leptospirosis humana em América Central, América do Sul e do Caribe

Resumo. Para identificar e descrever o estado epidemiológico da leptospirosis humana o doença de Weil, realizou-se pesquisas de publicações científicas e relatórios de entes reguladoras de saúde, durante o período 2006-2013. A extração da informação foi independente e realizou-se uma lista de verificação para avaliar a qualidade metodológica dos artigos encontrados. O país com maior prevalência foi Trinidad \& Tobago (22 casos por 100.000 habitantes) e a maior proporção de casos foi em Guyana (60\%). Em Colômbia, o departamento com maior proporção de casos foi Antioquia $(85,7 \%$ ) e o de maior soroprevalência, Córdoba (67,9\%). Para o diagnóstico, a técnica mais utilizada é a aglutinação microscópica e o possível fator de risco é pelo contacto com animais. A informação analisada apresentou diversos aspetos epidemiológicos, dificultando a sua unificação. Para alguns países, é evidente o interesse e a consciência académica e governamental na área de saúde pública.

Palavras-chave: Leptospirosis humana; prevalência; fator de risco; diagnóstico; Colômbia. 